University of Massachusetts Amherst

ScholarWorks@UMass Amherst

1993

\title{
Calibration of the Drying and Pyrolysis Temperatures for Graphite Furnace Atomic Absorption Spectrometry by Direct Observation of the Melting of Compounds
}

Julian Tyson

University of Massachusetts Amherst

R M. LaRue

University of Massachusetts Amherst

Follow this and additional works at: https://scholarworks.umass.edu/chem_faculty_pubs

Part of the Chemistry Commons

\section{Recommended Citation}

Tyson, Julian and LaRue, R M., "Calibration of the Drying and Pyrolysis Temperatures for Graphite Furnace Atomic Absorption Spectrometry by Direct Observation of the Melting of Compounds" (1993). Spectrochimica Acta Part B. 1310.

Retrieved from https://scholarworks.umass.edu/chem_faculty_pubs/1310 


\section{Calibration of the drying and pyrolysis temperatures for graphite furnace atomic absorption spectrometry by direct observation of the melting of compounds}

(Received 4 January 1993; accepted 13 March 1993)

\section{INTRODUCTION}

A TYPICAL graphite furnace atomic absorption spectrometry (GFAAS) program usually consists of three main stages; a drying stage, an ashing stage, and an atomization stage. During the drying stage, evaporation of the solvent occurs and a solid residue is left within the graphite tube. The temperature of the drying stage is chosen so that the evaporation of solvent is as rapid as possible without causing the sample to undergo spattering within the graphite tube, leading to possible loss of sample and poor precision arising from atomization of the sample from parts of the graphite tube that are heated at a different rate.

In order to decrease the cycle time of the furnace program, hot injection procedures, in which the sample solution is introduced into a pre-heated graphite tube, have been devised [1-5]. Typically, the graphite tube is pre-heated to a temperature of $110-120^{\circ} \mathrm{C}$, a temperature below which drying does not occur quickly and above which spattering of sample occurs. This stage is usually followed by a short stage of about $40-50^{\circ} \mathrm{C}$ higher in order to remove water vapor. In addition to reduced cycle times, improvements in sensitivity of up to tenfold have been observed [6]. In addition to the introduction of solutions into a hot tube, it has been shown that it is possible to trap volatile hydrides on the interior of a graphite furnace, thereby achieving a significant increase in sensitivity [7-10]. Furnace temperatures between 300 and $1000^{\circ} \mathrm{C}$ are required.

Of course, it is well recognized that accurate temperature measurements are essential in any fundamental study of the operating characteristics of a particular furnace design or in a study of atomization mechanisms. The majority of such studies have been concerned with measurements of elevated temperatures at which vaporization processes involving analyte species occur. In these studies it may be necessary to measure the temperature of the tube wall (at a specified location) or the temperature of a L'vov platform, or of the vapor within the furnace. Temperature measurement procedures reported in the relevant literature up to 1983 have been surveyed by SLAvin [11]. For measurement of the tube wall temperature, methods based on the emissivity have been described including (a) the use of optical pyrometers, and (b) measurement of the emission of the tube at two wavelengths. Such procedures are more difficult to apply to the measurement of a platform, as the situation of interest is the extent to which the platform temperature lags behind that of the vapor during the atomization process and thus, by definition, the platform is not in thermal equilibrium with the rest of the system. ChaKrabarti and coworkers considered this problem and devised a procedure in which the melting of pure metals, observed by the reflectivity in an interrogating $\mathrm{He}-\mathrm{Ne}$ laser beam was used to determine the heating characteristics of the platform [12]. Measurements of the vapor temperature have been based on the use of the two-line atomic spectroscopic method with a variety of thermometric probe species [13]. More recently, the technique of coherent anti-Stokes Raman scattering has been applied to the measurement of temperature profiles in the furnace vapor [14].

There would appear to be no reports of the temperature measurement of platforms at the low temperature associated with the drying and ashing stages of the furnace cycle. When such platforms are used, manufacturers recommend that ramp times be shortened compared with those used for wall atomization, on the basis that the platform heats more slowly than the tube wall. The final temperature for drying would be about $20-40^{\circ} \mathrm{C}$ above the boiling point of the solvent.

In several of the current generation of graphite furnace atomic absorption spectrometers there is no direct measurement of the temperature of the tube (or of the platform or of the gas inside the tube). The appropriate voltage needed to heat the graphite tube to a particular temperature is stored in a look-up table in the instrument's operating software. The values are based on 
extensive previous experiments by the manufacturer in which the heating characteristics of a number of graphite tubes were measured with either a thermocouple or with an optical pyrometer, for higher temperatures at which significant black body emission is produced.

For example, for the Perkin-Elmer HGA-600 graphite furnace unit, the system has stored in memory a table of temperatures and the corresponding voltage which must be applied to heat the graphite tube to that temperature. The system then applies that voltage across the tube to heat the tube to that temperature. The temperature of the tube may be varied in $10^{\circ} \mathrm{C}$ intervals from ambient up to $3000^{\circ} \mathrm{C}$. There is no control over the temperature other than the control exercised over the applied voltage. At atomization temperatures (greater than about $1800^{\circ} \mathrm{C}$ ), the emission from the tube is measured with an optical pyrometer. Prior to the analytical run, the appropriate voltage from the look-up table, corresponding to the atomization temperature set, is applied to the tube and the optical pyrometer reading is stored. This value is then compared with the pyrometer reading during the atomization stage of the analytical run and is used to control the duration of the maximum power heating stage (i.e. triac on all the time) before switching back to conventional heating under voltage control.

In this paper, a simple method is described for checking the furnace temperature during the early stages of the sample thermal treatment. The procedure is based on the observation of the melting of a set of compounds of known melting point.

\section{EXPERIMENTAL}

A Perkin-Elmer 5100 atomic absorption spectrometer equipped with Zeeman background correction, a Perkin-Elmer HGA-600 furnace and a Perkin-Elmer AS-60 autosampler was used. The entire system was controlled by a DEC station 316sx computer which utilized GEM desktop software. Pyrolytically coated graphite tubes were used. These were purchased from Perkin-Elmer (Catalog 0290-1821) and from Solutions, Inc. (Code SA4010) (Fenton, MO).

Eleven compounds were chosen for the study based on availability and suitability of melting point. As far as was practical, compounds were selected so that pairs of compounds had similar melting points. These include 8-hydroxyquinoline (Fisher certified), D-camphor (Eastman Kodak), L-menthol (ICN Pharmaceuticals, Inc.), phenol (Mallinckrodt), L-proline (Eastman Kodak), anthrone (Fisher ACS certified), benzoic acid (Fisher USP/FCC), azelaic acid (Eastman Kodak), benzoin (Eastman Kodak), urea (Mallinckrodt), and citric acid (J. T. Baker).

\section{Procedure}

Milligram amounts of each compound were loaded into the graphite tube manually with the aid of a Flexi-straw (Sweetheart, Chicago, IL) cut into the shape of a spatula at the end. The right hand quartz window of the furnace unit was removed to allow access to the graphite tube. The Flexi-straw was inserted into the graphite tube until visible through the dosing hole. The Flexi-straw was then inverted, depositing the sample in the middle of the graphite tube, and the window replaced.

A temperature program of $1^{\circ} \mathrm{C} \mathrm{s}^{-1}$ was run up to a suitable maximum temperature. This temperature was, in most cases, $100^{\circ} \mathrm{C}$ higher than the literature value for the melting point of the compound. Visual observation of changes occurring within the tube were performed with the aid of a mirror. The melting point was taken as that temperature at which the compound first began to undergo visible transition from liquid to solid. A typical furnace program is shown in Table 1. Six replicate measurements were performed for each compound. A clean-up stage in which the temperature was raised to $2600^{\circ} \mathrm{C}$ for $5 \mathrm{~s}$ was performed every three replicates or if the graphite tube performance began to show inconsistent results. If the application of the clean-up stage could not improve the performance of the graphite tube, then a new tube was inserted. The choice of a hollow cathode lamp (HCL) was unimportant as no absorbance measurements were taken. A lamp had to be present for the system to operate. Several different HCLs were used throughout the experiment, but these had no effect on the melting point determinations and were operated at currents less than normally required so as not to decrease the lamp lifetime. The autosampler was not disconnected from the system but allowed to inject air.

Figure 1 was produced with the aid of Cricket Graph version 1.3, a graphics software program available from Great Valley Corporate Center, Malvern, PA. 
Table 1. A typical GFAAS program for melting point determination. Stage $7 b$ occurs if a clean-up stage is desired, otherwise $7 \mathrm{a}$ is used. This program would be used for L-proline. Stages could be removed for compounds with lower melting points

\begin{tabular}{cccc}
\hline Stage & $\begin{array}{c}\text { Temperature } \\
\left({ }^{\circ} \mathrm{C}\right)\end{array}$ & Ramp (s) & Hold (s) \\
\hline 0 & 20 & - & - \\
1 & 100 & 80 & 0 \\
2 & 150 & 50 & 0 \\
3 & 200 & 50 & 0 \\
4 & 250 & 50 & 0 \\
5 & 300 & 50 & 0 \\
6 & 350 & 50 & 0 \\
$7 \mathrm{a}$ & 20 & 1 & 0 \\
$7 \mathrm{~b}$ & 2600 & 1 & 5 \\
\hline
\end{tabular}

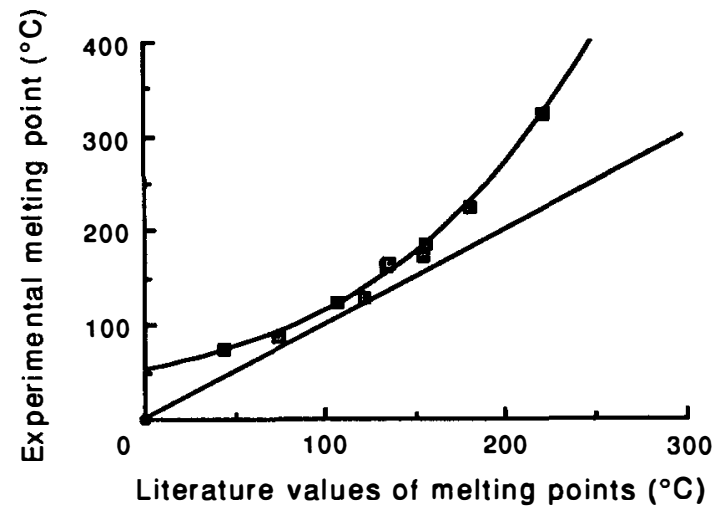

Fig. 1. Experimental melting points vs the literature values of the melting points for the eleven compounds studied.

\section{Results ANd Discussion}

The literature values [15] for the melting points of the eleven compounds and the corresponding experimental values are shown in Table 2 . In cases where the manufacturer provided a melting point, these were used in place of the literature values. The results are shown graphically in Fig. 1, where a third-order polynomial curve fit produced the equation for the curve, $y=51.127$ $+0.42492 x+\left(9.4281 \times 10^{-4}\right) x^{2}+\left(1.2004 \times 10^{-5}\right) x^{3}$. It may be seen that the best agreement

Table 2. Literature and experimental melting point values for the eleven compounds. The \pm values represent standard deviations for 6 replicates

\begin{tabular}{lcc}
\hline Compound & Literature value $\left({ }^{\circ} \mathrm{C}\right)$ & Experimental value $\left({ }^{\circ} \mathrm{C}\right)$ \\
\hline L-menthol & 44 & $75 \pm 5$ \\
Phenol & 44 & $75 \pm 5$ \\
8-hydroxyquinoline & 74 & $87 \pm 5$ \\
Azelaic acid & 106 & $124 \pm 10$ \\
Benzoic acid & 122 & $130 \pm 3$ \\
Benzoin & 133 & $163 \pm 3$ \\
Urea & 135 & $164 \pm 7$ \\
Citric acid & 154 & $174 \pm 13$ \\
Anthrone & 155 & $186 \pm 17$ \\
D-camphor & 180 & $225 \pm 8$ \\
L-proline & 220 & $322 \pm 13$ \\
\hline
\end{tabular}


between literature and experimental melting point values occurs in the range $100-150^{\circ} \mathrm{C}$. In all cases, the temperature indicated by the computer display was higher than the real temperature of the tube wall. This discrepancy was especially noticeable at the higher end of the temperature range used. For example, the experimentally indicated melting point for L-proline was approximately $100^{\circ} \mathrm{C}$ higher than the literature value, whereas for L-menthol and phenol, the experimentally indicated melting temperature was about $30^{\circ} \mathrm{C}$ higher than the corresponding literature values. It should be noted that these points are possibly less reliable than the others because pairs of compounds with similar melting points were not available.

One of several possible reasons for this discrepancy is the heat capacity of the relatively large amount of sample material introduced into the furnace in comparison with the normal sample mass. Thus by the time that melting was observed the temperature program would indicate a higher temperature. However, L-proline did not melt until the indicated temperature was $100^{\circ} \mathrm{C}$ above the true melting point, this would mean that a further $100 \mathrm{~s}$ of time had elapsed at a program ramp rate of $1^{\circ} \mathrm{C} \mathrm{s}^{-1}$. Such a long lag time seems unlikely.

For hot injection procedures, it is required that the temperature of the graphite tube be maintained at about $120^{\circ} \mathrm{C}$. There would be little error associated with this procedure. For example, benzoic acid, with a melting point of $122^{\circ} \mathrm{C}$ melts at a displayed temperature of $130^{\circ} \mathrm{C}$. The second stage of the hot injection process, in which adsorbed water vapor is removed, may suffer a greater error. A temperature of around $160^{\circ} \mathrm{C}$ is required but for citric acid and anthrone, both having melting points near $160^{\circ} \mathrm{C}$, melting was not observed until a displayed temperature of $174^{\circ} \mathrm{C}$ was reached. These results indicate that the temperature should be set slightly higher to achieve the desired temperature within the graphite tube.

A second possible reason for the discrepant results is that the temperature of the cooling water has an active role to play. This parameter was not investigated further, but is one which is clearly not under very good control when interlaboratory comparisons of instrument performance of this kind are made. To remove this source of variation, maybe manufacturers should consider making the recirculating cooling system an integrated part of the instrument.

To avoid systematic errors, two strategies were adopted. Firstly the set of compounds chosen contained several pairs which have similar or identical melting points. These were L-menthol and phenol, benzoin and urea, and citric acid and anthrone. In these pairs, the melting point temperatures differ by no more than two degrees. In the case of L-menthol and phenol, identical experimental melting points were obtained. The benzoin and urea pair showed an experimental melting point difference of $1^{\circ} \mathrm{C}$. The citric acid and anthrone pair showed a larger difference in mean values, but because of the greater uncertainties in these values, the difference is not significant. Secondly, to avoid any possible effect due to the condition of the graphite tube, the compounds were examined in random order. In addition two different sources of graphite tubes were utilized, namely Perkin-Elmer and Solutions, Inc. Tubes from the two sources gave similar results and had similar tube lifetimes.

In most instances, the transition between solid and liquid was readily apparent. However, the melting of some compounds was not as easily recognized, and this is reflected in the large standard deviations observed for several compounds such as azelaic acid, citric acid and anthrone.

The detection of melting could be considerably improved if it was possible to monitor absorbance continually throughout the dry and char stages of the furnace program. This is not possible with the instrument used in these studies. By suitable orientation of crystals and alignment of the hollow cathode lamp beam, it should be possible to detect melting by a change in the light throughput. This might enable the mass of probe material to be reduced and could extend the scope of the procedure up to temperatures at which the furnace emits visible radiation, which makes visible observation of the melting process difficult.

\section{SUMMARY}

In routine operation, the temperature of the graphite tube in an electrothermal atomizer atomic absorption spectrometer is not measured directly. The various temperatures selected for a particular analysis program are assumed to be achieved based on look-up tables, stored in memory, in which the temperature vs applied voltage data, averaged over a number of test furnace tubes, is stored. A method for the direct calibration of the temperature within the graphite tube over a range of $44-220^{\circ} \mathrm{C}$ is presented in which a few $\mathrm{mg}$ of a solid of known melting point were inserted within the graphite tube and heated slowly. Pairs of compounds with close melting points were selected. Visual observation of the transition from solid to liquid was made and a temperature calibration for the graphite tube constructed from the results. It 
was found that the temperature within the graphite tube lagged slightly behind the temperature displayed, which was most accurate within the range $100-150^{\circ} \mathrm{C}$.

\section{REFERENCES}

[1] U. K. Kunwar, D. Littlejohn and D. J. Halls, J. Anal. At. Spectrom. 4, 153 (1989).

[2] P. Bermejo-Barrera, E. Beceiro-Gonzalez and A. Bermejo-Barrera, Anal. Chim. Acta 236, 475 (1990).

[3] U. K. Kunwar, D. Littlejohn and D. J. Halls, Talanta 37, 555 (1990).

[4] M. B. Knowles, J. Anal. At. Spectrom. 4, 257 (1989).

[5] W. Slavin, D. C. Manning and G. R. Carnrick, Spectrochim. Acta 44B, 1237 (1989).

[6] P. Apostoli, L. Alessio, M. D. Farra and P. L. Fabbri, J. Anal. At. Spectrom. 3, 471 (1988).

[7] L. Zhang, Z.-M. Ni and X.-Q. Shan, Spectrochim. Acta 44B, 339 (1989).

[8] L. Zhang, Z.-M. Ni and X.-Q. Shan, Spectrochim. Acta 44B, 751 (1989).

[9] P. S. Doidge, B. T. Sturman and T. M. J. Rettberg, J. Anal. At. Spectrom. 4, 251 (1989).

[10] R. Sturgeon, S. N. Willie, G. I. Sproule, P. T. Robinson and S. S. Berman, Spectrochim Acta 44B, 667 (1989).

[11] W. Slavin, Graphite Furnace AAS A Source Book, 2nd Edn. Perkin-Elmer, Norwalk (1991).

[12] S. Wu, C. L. Chakrabarti and J. T. Rogers, Spectrochim. Acta 39B, 415 (1984).

[13] R. E. Sturgeon and C. L. Chakrabarti, Spectrochim. Acta 32B, 231 (1977).

[14] N. Wentzel, B. Trautman, H. Grosse-Wilde, G. Schlemmer, B. Welz and G. Marowsky, Opt. Comm. 68, 75 (1988).

[15] D. R. Lide (Ed.), Handbook of Chemistry and Physics, 71st Edn. CRC Press, Boca Raton, FL (1990).

Department of Chemistry

University of Massachusetts at Amherst

Amherst

MA 01003

U.S.A.
R. M. LARUE

J. F. TYSON 